\title{
Fibromyalgia: A Mini Review
}

\author{
Teresa Pugliese*, Filippo Familiari, Olimpio Galasso and Giorgio Gasparini \\ Department of Orthopaedic and Trauma Surgery, "Magna Græcia" University of Catanzaro, Catanzaro, Italy \\ "Corresponding author: Teresa Pugliese, MD, Department of Orthopaedic and Trauma Surgery, "Magna Græcia" University of Catanzaro, Campus "S.Venuta”, V.le \\ Europa (Loc. Germaneto), 88100 Catanzaro, Italy, Tel: +39 0961/3647001, Fax: +39 0961/3647104; E-mail: dott.teresapugliese@libero.it
}

Rec date: July 16, 2015; Acc date: August 01, 2015; Pub date: August 08, 2015

Copyright: (C) 2015 Pugliese T, et al. This is an open-access article distributed under the terms of the Creative Commons Attribution License, which permits unrestricted use, distribution, and reproduction in any medium, provided the original author and source are credited.

\section{Mini Review}

Fibromyalgia (FM) is estimated to affect more than 5 million people in the United States of America (2-5\% of the adult population) [1,2], making it one of the most common chronic widespread pain disorders $[3,4]$. Female patients are affected at least 6 times more often than male patients, and the prevalence of FM has been shown to increase with age [5]. Patients often have associated symptoms such as fatigue, nonrestorative sleep, cognitive dysfunction, and mood disorder, which are present to variable degrees in individual patients [6].

Although the pathogenesis of FM has not been totally defined, several authors consider it either a disorder of the pain modulation centre of or an altered central nervous system processing in response to nociceptive stimuli [7-11]. Recent evidence has suggested the contribution of environmental factors acting on genetically predisposed individuals [12]. Moreover, because FM is a chronic painful syndrome, it has a significant negative impact on patients' quality of life [3,13-15]. Chronic widespread pain remains the core symptom of FM, reported as diffuse, fluctuating and with neuropathic features among some patients.

Fatigue, which is tightly connected with sleep disorder, is present in more than $90 \%$ of patients with FM, whereas abnormal sleep with prolonged sleep latency, sleep disturbance and fragmented sleep occurs in up to $75 \%$ of patients $[6,16]$. Furthermore, FM is now recognized as a polysymptomatic distress syndrome; it is associated with pain and includes poor working memory, free recall and verbal fluency, spatial memory alterations, mood disorder, including depression and anxiety [17]. Other conditions causing pain can occur concomitantly, including irritable bowel syndrome, migraine and dysmenorrhea [18]. Patients may also experience lower urinary tract symptoms, myofascial pain involving the face and temporomandibular pain [18]. The 1990 American College of Rheumatology (ACR) classification criteria required 3 months or more of widespread pain and pain on palpation of at least 11 of 18 tender point sites. The 1990 ACR criteria have been used to identify patients for clinical trials and to diagnose FM in patients in clinical settings [19].

In 2010, these criteria have been updated to include a widespread pain index and a symptom severity scale and eliminate the tender point examination [20]. Consequently, due to its varied symptomatology and the multifactorial nature of its pathogenesis, treatment of FM requires a multidisciplinary approach and should include non-pharmacological treatment as well as pharmacological interventions [21]. The pharmacological therapy currently recommended for this disease includes antidepressants, calciumchannel modulators, muscle relaxants, and analgesics [22]. However, many patients fail to respond or they have side effects associated with the long-term use of these drugs. Therefore, there is growing interest towards non-pharmacological therapy and alternative and complementary therapy. Several non-pharmacological therapeutic modalities are used in such patients: physiotherapy, whole body cryotherapy, complementary and alternative medicine, supervised aerobic physical activity and cognitive-behavioral therapy [23,24]. In conclusion, the treatment of this disorder is difficult and cannot be standardized because of the unknown etiology of FM. Furthermore, a multidisciplinary treatment approach including physical and medical therapeutic interventions should be individualized for FM patients based on their symptoms.

\section{References}

1. Lawrence RC, Felson DT, Helmick CG, Arnold LM, Choi H, et al. (2008) Estimates of the prevalence of arthritis and other rheumatic conditions in the United States. Part II. Arthritis Rheum 58: 26-35.

2. Wolfe F, Ross K, Anderson J, Russell IJ, Hebert L (1995) The prevalence and characteristics of fibromyalgia in the general population. Arthritis Rheum 38: 19-28.

3. Burckhardt CS, Clark SR, Bennett RM (1991) The fibromyalgia impact questionnaire: development and validation. J Rheumatol 18: 728-733.

4. Ghavidel-Parsa B, Bidari A, Amir Maafi A, Ghalebaghi B (2015) The Iceberg Nature of Fibromyalgia Burden: The Clinical and Economic Aspects. Korean J Pain 28: 169-176.

5. McNally JD, Matheson DA, Bakowsky VS (2006) The epidemiology of self-reported fibromyalgia in Canada. Chronic Dis Can 27: 9-16.

6. Mease P, Arnold LM, Choy EH, Clauw DJ, Crofford LJ, et al. (2009) Fibromyalgia syndrome module at OMERACT 9: domain construct. J Rheumatol 36: 2318-2329.

7. Dadabhoy D, Crofford LJ, Spaeth M, Russell IJ, Clauw DJ (2008) Biology and therapy of fibromyalgia. Evidence-based biomarkers for fibromyalgia syndrome. Arthritis Res Ther 10: 211.

8. Nielsen LA, Henriksson KG (2007) Pathophysiological mechanisms in chronic musculoskeletal pain (fibromyalgia): the role of central and peripheral sensitization and pain disinhibition. Best Pract Res Clin Rheumatol 21: 465-480.

9. Pillemer SR, Bradley LA, Crofford LJ, Moldofsky H, Chrousos GP (1997) The neuroscience and endocrinology of fibromyalgia. Arthritis Rheum 40: 1928-1939.

10. Staud R, Vierck CJ, Cannon RL, Mauderli AP, Price DD (2001) Abnormal sensitization and temporal summation of second pain (windup) in patients with fibromyalgia syndrome. Pain 91: 165-175.

11. Larson AA, Pardo JV, Pasley JD (2014) Review of overlap between thermoregulation and pain modulation in fibromyalgia. Clin J Pain 30: 544-555.

12. Buskila D, Sarzi-Puttini P (2006) Biology and therapy of fibromyalgia. Genetic aspects of fibromyalgia syndrome. Arthritis Res Ther 8: 218.

13. Perrot S, Dumont D, Guillemin F, Pouchot J, Coste J; French Group for Quality of Life Research (2003) Quality of life in women with fibromyalgia syndrome: validation of the QIF, the French version of the fibromyalgia impact questionnaire. J Rheumatol 30: 1054-1059.

14. Picavet HS, Hoeymans N (2004) Health related quality of life in multiple musculoskeletal diseases: SF-36 and EQ-5D in the DMC3 study. Ann Rheum Dis 63: 723-729. 
Citation: Pugliese T, Familiari F, Galasso O, Gasparini G (2015) Fibromyalgia: A Mini Review . J Arthritis 4: 159. doi:

Page 2 of 2

15. Wolfe F, Hawley DJ, Goldenberg DL, Russell IJ, Buskila D, et al. (2000) The assessment of functional impairment in fibromyalgia (FM): Rasch analyses of 5 functional scales and the development of the FM Health Assessment Questionnaire. J Rheumatol 27: 1989-1999.

16. Moldofsky H (2008) The significance of the sleeping-waking brain for the understanding of widespread musculoskeletal pain and fatigue in fibromyalgia syndrome and allied syndromes. Joint Bone Spine 75: 397-402.

17. Fitzcharles MA, Ste-Marie PA, Pereira JX; Canadian Fibromyalgia Guidelines Committee (2013) Fibromyalgia: evolving concepts over the past 2 decades. CMAJ 185: E645-651.

18. Pöyhiä R, Da Costa D, Fitzcharles MA (2001) Previous pain experience in women with fibromyalgia and inflammatory arthritis and nonpainful controls. J Rheumatol 28: 1888-1891.

19. Wolfe F, Smythe HA, Yunus MB, Bennett RM, Bombardier C, et al. (1990) The American College of Rheumatology 1990 Criteria for the Classification of Fibromyalgia. Report of the Multicenter Criteria Committee. Arthritis Rheum 33: 160-172.
20. Wolfe F, Clauw DJ, Fitzcharles MA, Goldenberg DL, Katz RS, et al. (2010) The American College of Rheumatology preliminary diagnostic criteria for fibromyalgia and measurement of symptom severity. Arthritis Care Res (Hoboken) 62: 600-610.

21. Crofford LJ, Appleton BE (2001) Complementary and alternative therapies for fibromyalgia. Curr Rheumatol Rep 3: 147-156.

22. Häuser W, Walitt B, Fitzcharles MA, Sommer C (2014) Review of pharmacological therapies in fibromyalgia syndrome. Arthritis Res Ther 16: 201

23. Angst F, Brioschi R, Main CJ, Lehmann S, Aeschlimann A (2006) Interdisciplinary rehabilitation in fibromyalgia and chronic back pain: a prospective outcome study. J Pain 7: 807-815.

24. Arnold LM, Bradley LA, Clauw DJ, Glass JM, Goldenberg DL (2008) Multidisciplinary care and stepwise treatment for fibromyalgia. J Clin Psychiatry 69: e35. 